\title{
Lithium in Bipolar Disorder: Optimizing Therapy Using Prolonged-Release Formulations
}

\author{
Paolo Girardi ${ }^{1,2,3} \cdot$ Roberto Brugnoli $^{1,2} \cdot$ Giovanni Manfredi $^{2,3} \cdot$ Gabriele Sani $^{1,2,3}$
}

Published online: 21 October 2016

(C) The Author(s) 2016. This article is published with open access at Springerlink.com

\begin{abstract}
Lithium has been a gold standard in the treatment of bipolar disorder (BD) for several decades. Despite a general reduction in the use of lithium over the past several years, it is effective in the management of both manic and depressive episodes in BD and continues to be recommended as a first-line mood stabilizer. This review provides an overview of the pharmacology of lithium and highlights its clinical profile in the management of $\mathrm{BD}$, focusing on the potential advantages of prolonged-release (PR) versus immediate-release (IR) formulations of lithium. A literature search using PubMed was performed to identify articles describing IR and PR lithium in BD using specific search terms like 'lithium', 'prolonged-release', 'sustained-release', 'extended-release', 'bipolar disorder', 'adherence' and 'compliance'. Relevant pharmacodynamic and pharmacokinetic data were also included. Several clinical trials suggested that lithium is effective in the treatment of acute mania and prophylaxis of $\mathrm{BD}$ and reduces the risk of suicide in patients with $\mathrm{BD}$; it may also be used in combination with other drugs in the treatment of bipolar depression. Treatment with lithium must be monitored to avoid lithium-associated toxicity. The prolonged PR formulation of lithium has several advantages including consistent serum lithium concentrations, fewer adverse events and improved adherence to
\end{abstract}

Paolo Girardi

paolo.girardi@uniroma1.it

1 Department of Neuroscience, Mental Health and Sensory Organs (NESMOS), School of Medicine and Psychology, Sapienza University of Rome, Rome, Italy

2 Psychiatric Department of Saint Andrea Hospital of Rome, Via di Grottarossa 1037, 00189 Rome, Italy

3 Centro Lucio Bini, Rome, Italy therapy. Although direct comparative studies between PR and IR formulations of lithium are primarily limited to pharmacokinetic studies, PR formulation of lithium provides potential advantages over IR formulation and can be effectively used in the management of $\mathrm{BD}$ with lesser adverse events.

\section{Key Points}

Lithium is considered as a gold standard therapy for bipolar disorder; it is used as a first-line therapy in the prophylaxis and treatment of acute mania and depression, and is effective in reducing the risk of suicide in patients with bipolar disorder

Treatment with lithium must be monitored to avoid the adverse events associated with the therapy; prolonged-release lithium formulations have an advantage of providing more consistent serum concentrations leading to fewer adverse events and convenience of dosage regimen with improved adherence to therapy, and can be effectively used in treatment of bipolar disorder

\section{Introduction}

Bipolar disorder (BD) is a chronic, recurrent mood disorder that typically develops in early adulthood and is associated with substantial morbidity and mortality $[1,2]$. It can be further classified into bipolar I disorder, comprising fullblown manic or mixed episodes, usually accompanied by 
major depression, and bipolar II disorder, which is characterized by major depression and at least one episode of hypomania (a milder form of mania) [3]. In addition, rapidcycling $\mathrm{BD}$, which can come and go, is a severe form of the condition characterized by four or more mood disorder episodes (major depression, mania, hypomania or mixed states involving symptoms of both mania and depression) during the previous year [3, 4]. Symptoms of BD are severe and include unusual shifts in mood, energy, activity levels and the ability to carry out activities of daily living [4]. Manic episodes may involve an overly happy or outgoing mood, extreme irritability and behavioural changes, such as talking very quickly, switching from one idea to another, being easily distracted and requiring little sleep. Depressive episodes may involve an overly long period of feeling sad or hopeless, as well as behavioural changes such as tiredness, difficulty concentrating and making decisions, and suicidal thoughts [4].

BD is not only disabling, affecting daily functioning and potentially leading to loss of employment [5-7], it is also relatively common and has a high rate of co-morbid medical illness that increases mortality $[1,2,4,8]$. It affects $2.4 \%$ of the global population and is the fourth leading cause of disability and death in10-24-year-olds in the world $[9,10]$. In the US, the lifetime prevalence of bipolar I or II disorder is estimated at $3.9 \%$ [2]. Data from Sweden show about a 2-2.5-fold increase in mortality among individuals with BD $[8,11]$. Suicide contributed to this statistic, but half of the excess deaths resulted from natural causes [8].

Treatment of BD needs to be individualized and includes pharmacological agents as well as psychosocial interventions $[4,12]$. Pharmacological treatment options to control symptoms and/or prevent illness recurrence in the management of BD include lithium, anticonvulsants (e.g., valproate, lamotrigine, carbamazepine), atypical antipsychotics (e.g., olanzapine, aripiprazole, quetiapine, risperidone, ziprasidone), and in some cases antidepressants (e.g., fluoxetine, paroxetine, sertraline, bupropion), although the latter may increase the risk of manic or hypomanic episodes, especially if antidepressants are used alone [4, 12]. Combination therapy is often used in clinical practice [13], especially for patients with an inadequate response to monotherapy. First-line pharmacotherapy for BD is usually a mood stabilizer (i.e., lithium or an anticonvulsant, such as valproate) $[4,12,14]$. However, there are often differences between guidelines with respect to recommended treatment algorithms for BD and other psychiatric conditions [15]. Nevertheless, and despite a general reduction in lithium use over several years, lithium continues to be recommended as a first-line mood stabilizer [14, 15].

Lithium has been a widely used therapy for BD for several decades and is effective in the management of both manic and depressive episodes $[4,16,17]$. While at present there is a lack of detailed information/studies on the prolonged-release (PR) lithium preparation, it appears that this formulation of lithium may provide several potential advantages over the immediate-release (IR) formulations.

The objective of this review is to provide an overview of the pharmacology of lithium and review its clinical profile in the management of $\mathrm{BD}$, focusing on the potential advantages of PR versus IR formulations of lithium.

A literature search was performed to identify articles describing lithium and its use in BD. Relevant medical literature on lithium (IR and PR formulations) was identified by searching PubMed, bibliographies from published literature and websites (searches last updated 17 July 2015). Additional information was also included from relevant papers known to the authors. Search terms included 'lithium', 'prolonged-release', 'sustained-release', 'extended-release', 'bipolar disorder', 'adherence' and 'compliance'. Clinical trial selection included studies in patients with BD who received lithium (IR or PR formulations). Where data permitted, studies using PR formulations were preferred, as were well designed comparative trials with appropriate statistical methodology and recent meta-analyses. Relevant pharmacodynamic and pharmacokinetic data were also included.

\section{Overview of Pharmacology of Lithium}

Lithium is a mood-stabilizing agent that is used in the management of acute manic or hypomanic episodes and in the prophylaxis against bipolar affective disorders [18]. Additional therapeutic indications may also apply, depending on the country and specific lithium product; therefore, local prescribing information should always be consulted. Lithium is an alkali metal available for medical use as lithium carbonate or lithium citrate. Despite lithium being available for about 60 years in clinical practice, its mechanism of action is not well understood because it acts at a number of targets and across a range of neurotransmitter and non-transmitter systems [19]. Around the synapse, lithium modulates neurotransmitter receptor-mediated processes, and modifies the production and turnover of certain neurotransmitters, particularly dopamine, glutamate and GABA [19]. Other pharmacodynamic effects of lithium, including a reduction in thyroid activity, modification of serum electrolyte concentrations (e.g., calcium, magnesium) and modest impairment of cognitive function (e.g., vigilance, alertness, learning and short-term memory), may lead to adverse events in patients with BD who receive lithium [20-22] (see Sect. 4). Lithium has a narrow therapeutic window and therefore requires therapeutic drug monitoring (see Sect. 5). 
The pharmacokinetic properties of lithium have been reviewed in some detail [21]. The oral bioavailability of lithium is $\sim 80-100 \%$. It is mainly absorbed through the stomach and is extensively excreted in urine [23, 24]. In general, concomitant ingestion of food tends to increase lithium absorption. IR formulations of lithium are rapidly absorbed and achieve peak serum concentrations $\left(C_{\max }\right) \sim 1-2 \mathrm{~h}$ after oral administration $\left(t_{\max }\right)$. In contrast, $t_{\max }$ values for PR formulations of lithium are $\sim 4-5 \mathrm{~h}$. The serum lithium concentration peak:trough ratio is $\sim 1.9$ for IR formulations compared with $\sim 1.6$ for PR formulations. Despite the somewhat blunted (i.e., lower and less pronounced) $C_{\max }$ with lithium PR versus IR formulations (peak plasma concentrations of the PR formulation are 30-50\% lower than for IR formulations), the area under the serum concentration-time curve (AUC) values for comparable dosage regimens at steady state are generally similar. Thus, PR formulations provide more stable, consistent serum drug concentrations than IR formulations, but overall exposure is essentially equivalent over the dosage interval and with longterm administration [21]. While the movement of lithium ions across the blood-brain barrier is slow and a relatively small amount of circulating lithium reaches the brain, the levels of lithium that cross the blood-brain barrier are directly proportional to plasma levels of lithium [25]. However, there is accumulation of lithium in the brain with prolonged treatment and the plasma measurements poorly represent actual brain lithium concentrations over time [26]. Some lithium-related adverse events appear to be related to the rate of increase in serum lithium concentrations, suggesting that the slower rate of increase with PR formulations should provide a tolerability advantage over IR formulations (see Sect. 4).

The volume of distribution of lithium is $\sim 0.7-1.0 \mathrm{~L} / \mathrm{kg}$ and serum protein binding is thought to be negligible at therapeutic concentrations [27]. Lithium does not undergo hepatic metabolism and is almost exclusively eliminated by the kidneys as a free ion. The terminal elimination half-life $\left(t_{1 / 2 \beta}\right)$ is $\sim 18-36 \mathrm{~h}$ in individuals with normal renal function; the $t_{1 / 2 \beta}$ generally lengthens as the duration of therapy increases [27]. There are a number of clinically significant drug interactions with lithium, the most important of which are those that increase its retention in the body and lead to lithium toxicity (e.g., thiazide and loop diuretics, nonsteroidal anti-inflammatory drugs [NSAIDs] and angiotensin converting enzyme [ACE] inhibitors) [21, 22, 28].

\section{Efficacy of Lithium in Bipolar Disorder}

\subsection{Efficacy in Acute Mania}

Several trials determined the effect of treatment with lithium in the management of acute mania. Twelve randomized controlled trials of 3-4 weeks' duration with a total of 658 patients reported overall response rate ratios of 1.95 [95\% confidence interval (CI) 1.17-3.23] for lithium versus placebo and 1.96 (95\% CI 1.02-3.77) for lithium versus chlorpromazine [29]. Response rates were not significantly different for comparisons between lithium and carbamazepine or valproate, and the clinical trial evidence suggested that lithium should remain the first-line treatment for acute mania [29]. However, these studies had important deficiencies in terms of study design or outcomes reported (e.g., did not report efficacy in terms of currently recognized scoring systems or response rates) [29].

Two well designed trials provide the most rigorous scientific data demonstrating the superiority of lithium monotherapy to placebo in acute mania $[30,31]$. Both were three-arm studies that also involved an active comparator, one being divalproex sodium [30] and the other being quetiapine [31]. Assessment of efficacy [response rate or reduction (i.e., improvement) in Young Mania Rating Scale (YMRS) score] was after 3 [30, 31] and/or 12 weeks of treatment [31]. In terms of reducing symptoms of acute mania, lithium and divalproex sodium monotherapy were superior to placebo in the earlier trial [30], and lithium and quetiapine monotherapy were superior to placebo in the more recent study [31] (Table 1). However, it should be noted that the earlier trial included a relatively small number of lithium recipients, and a high proportion of patients in all three groups (48-61\%) did not complete the 3-week study, primarily because of lack of efficacy [30]. Also, compared with placebo, lithium was associated with a statistically significant improvement in Mania Rating Scale score at day 10 , but the between-group difference did not achieve statistical significance at the end of the 3-week study period [30]. Other data supporting results of these studies include a three-arm trial in bipolar I patients showing that mean YMRS score reductions were significantly greater with lithium than with topiramate or placebo [32], a meta-analysis demonstrating the efficacy of lithium in short-term trials in patients with moderate to severe manic episodes [33], and relatively small trials showing generally similar results between patients receiving lithium and those treated with various active comparators [31, 34, 35].

Lithium has also been evaluated as part of combination therapy (e.g., with risperidone, olanzapine or quetiapine) in the management of acute manic or mixed episodes, but findings from these trials are difficult to interpret because no distinction was made between mood stabilizers (i.e., lithium and valproate), which were evaluated as a single group [36-38]. However, data are available from a recent, randomized, double-blind trial in 356 bipolar I patients with acute mania who were randomized to receive lithium $(n=173)$ or placebo $(n=182)$ as add-on therapy to 
Table 1 Results of key randomized, double-blind, placebo-controlled trials with lithium in patients with acute mania

\begin{tabular}{|c|c|c|c|}
\hline Study (duration) & $\begin{array}{l}\text { Treatment } \\
\text { (no. of patients) }\end{array}$ & $\begin{array}{l}\text { YMRS score } \\
\text { change from } \mathrm{BL}^{\mathrm{a}}\end{array}$ & $\begin{array}{l}\text { YMRS response } \\
\text { (\% of patients with } \geq 50 \% \\
\text { reduction from } \mathrm{BL} \text { ) }\end{array}$ \\
\hline \multicolumn{4}{|l|}{ Monotherapy } \\
\hline \multirow[t]{3}{*}{ Bowden et al. [30] (3 weeks) } & Lithium (36) & $-10(27)^{\mathrm{b}}$ & $49^{\mathrm{c}} *$ \\
\hline & Divalproex sodium (69) & $-9 *(27)^{\mathrm{b}}$ & $48^{\mathrm{c} * *}$ \\
\hline & Placebo (74) & $-2(28)^{\mathrm{b}}$ & $25^{\mathrm{c}}$ \\
\hline \multirow[t]{3}{*}{ Bowden et al. [31] (3 weeks) } & Lithium (98) & $-15.2 * * *(33.3)$ & $53 * * *$ \\
\hline & Quetiapine (107) & $-14.6 * * *(32.7)$ & $53 * * *$ \\
\hline & Placebo (95) & $-6.7(34.0)$ & 27 \\
\hline \multicolumn{4}{|l|}{ Add-on therapy to quetiapine $\mathrm{XR}$} \\
\hline \multirow[t]{2}{*}{ Bourin et al. [39] (6 weeks) } & Lithium (173) & $-22.8 * * *(\mathrm{NR})$ & $79 * *$ \\
\hline & Placebo (176) & $-20.1(\mathrm{NR})$ & 68 \\
\hline
\end{tabular}

$B L$ baseline, $N R$ not reported, $X R$ extended-release, YMRS Young Mania Rating Scale

$* p<0.05, * * p<0.01, * * * p<0.001$ vs placebo

a Primary efficacy outcome

b Values estimated from a graph (and reported as 'Mania Rating Scale' scores)

c Percentage of patients with $\geq 50 \%$ improvement in the manic syndrome subscale score

quetiapine extended-release (XR) for 6 weeks [39]. For the primary endpoint of change in the YMRS total score from baseline to week 6 , lithium was shown to be superior to placebo, with a between-group difference of -2.69 $(p<0.001$; Table 1).

\subsection{Efficacy in the Prophylaxis of Bipolar Disorder}

Although early trials with lithium as maintenance therapy for the prophylaxis of BD also had significant design flaws, data are available from three well designed randomized, placebo-controlled, three-arm trials (active comparators were divalproex sodium in one trial [40] and lamotrigine in the other two [41, 42]) of 12-18 months' duration. Lithium and lamotrigine were superior to placebo for the prevention of relapse or recurrence of mood episodes requiring intervention (pharmacotherapy or electroconvulsive therapy) in bipolar I disorder patients with recent manic or hypomanic episodes [42] or with a recent major depressive episode [41] (Table 2). The difference between lithium and lamotrigine was not statistically significant for this outcome in either trial. In both studies, lithium was also statistically superior to placebo for prolonging the time to a manic or hypomanic episode, and lamotrigine was statistically superior to placebo for prolonging the time to a depressive episode [41, 42]. The study comparing lithium, divalproex sodium and placebo did not show statistically significant differences between the three groups for the primary outcome (time to intervention for any mood episode) [40] (Table 2). Various explanations have been suggested for the non-discriminant outcome of the trial, including a possible bias in the selection of patients, as well as the number and lack of homogeneity of previous and concomitant treatments permitted in the study [40].

Another randomized open-label trial (BALANCE [Lithium plus valproate combination therapy versus monotherapy for relapse prevention in bipolar I disorder]) compared the efficacy of lithium carbonate and valproate semisodium either alone or as combination therapy in the prevention of relapse in bipolar I disorder [43]. The results of this trial indicated that the lithium plus valproate combination therapy was more effective in preventing the relapse of bipolar I disorder compared with valproate monotherapy, and that lithium monotherapy was slightly superior compared with valproate monotherapy. The hazard ratio for the time to new intervention for an emerging mood episode was significantly lower in the combination group compared with valproate monotherapy $(0.59,95 \%$ CI $0.42-0.83 ; p=0.0023$ ), but was not lower for lithium monotherapy $(0.82,95 \%$ CI $0.58-1.17 ; p=0.27)$. It was further observed that the hazard ratio for lithium monotherapy was significantly lower than valproate monotherapy $(0.71,95 \%$ CI $0.51-1.00 ; p=0.0472)$.

Additional data demonstrating the efficacy of lithium for maintenance treatment are available from a large $(n=1172)$ randomized, double-blind trial in patients with bipolar I disorder and a current or recent manic, depressive or mixed episode that was treated with quetiapine for 4-24 weeks [44]. Patients who were stabilized were then randomized to continue quetiapine or switch to lithium or placebo for up to 2 years. The time to recurrence of any mood event was significantly $(p<0.0001)$ longer for quetiapine and lithium than placebo. Quetiapine and lithium also significantly increased time to recurrence of 
Table 2 Results of key randomized, double-blind, placebo-controlled trials with lithium and active comparators for maintenance treatment in bipolar I disorder

\begin{tabular}{|c|c|c|c|}
\hline Study (duration) & Treatment (no. of patients) & $\begin{array}{l}\text { Median time (days) } \\
\text { to intervention for } \\
\text { any mood episode }\end{array}$ & $\begin{array}{l}\text { Median time (weeks) } \\
\text { to } 50 \% \text { survival without } \\
\text { any mood episode }\end{array}$ \\
\hline \multirow[t]{3}{*}{ Bowden et al. [42] (18 months) } & Lithium (44) & $292 * *$ & \\
\hline & Lamotrigine (58) & $141^{*}$ & \\
\hline & Placebo (69) & 85 & \\
\hline \multirow[t]{3}{*}{ Calabrese et al. [41] (18 months) } & Lithium (120) & $170 *$ & \\
\hline & Lamotrigine (165) & $200 *$ & \\
\hline & Placebo (119) & 93 & \\
\hline \multirow[t]{3}{*}{ Bowden et al. [40] (12 months) } & Lithium (90) & & 24 \\
\hline & Divalproex sodium (187) & & 40 \\
\hline & Placebo (92) & & 28 \\
\hline
\end{tabular}

both manic events and depressive events compared with placebo.

Two separate studies indicated that long-term treatment with lithium is effective in patients with bipolar I and II subtypes [45], as well as patients with predominantly atypical or typical features [46]. In a prospective real-world treatment study (concomitant treatment permitted and no rigorous exclusion criteria exercised), 317 patients with BD were followed during lithium treatment for a mean of 6.35 years and outcomes were compared with prior longterm medical records (mean 8.38 years). Among both bipolar I and bipolar II subtypes, maintenance treatment with lithium provided long-term reductions in depressive and manic symptoms. Multivariate regression analyses indicated that benefit from lithium treatment was greatest for patients with type II disorder and those who received treatment earlier in their disease [45]. Another real-world study in the clinical setting examined whether symptom subtype in patients with BD had an effect on the effectiveness of long-term lithium therapy. Of 242 patients followed for 10 years, those patients with predominantly atypical features had similar symptom response to lithium as those patients with predominantly typical features [46].

Lithium is also reported to be more effective than placebo for the prevention of any episode of mood disturbance and of manic episodes, although the effect for prevention of depressive episodes was not statistically significant [47]. A randomized, double-blind, placebo-controlled interventional trial to evaluate the clinical and pathological effect of lithium in patients with BD and mood instability is currently ongoing [48]. Although data are somewhat limited, lithium may also improve the clinical symptoms of rapid cycling $\mathrm{BD}$ and can be effective in prophylaxis, but is unlikely to prevent recurrences of this disorder [49, 50].

\subsection{Efficacy in Acute Bipolar Depression}

Evidence for the efficacy of lithium in acute bipolar depression is limited. Several earlier studies reported the efficacy of lithium in the treatment of bipolar depression [51-53]. However, these studies were considered preliminary due to the short study durations and the fact that results were only speculative. Other double-blind, placebocontrolled studies demonstrated that quetiapine is more effective in the treatment of episodes of acute depression in adults with bipolar depression, but neither paroxetine nor lithium showed better efficacy compared with placebo $[54,55]$. Nevertheless, while the efficacy of lithium in this setting is controversial, it is recognized as a therapeutic option either as monotherapy or in combination with other antidepressants in the treatment of bipolar depression in guidelines and clinical practice [14, 56].

\subsection{Efficacy in Reducing Suicide Risk}

Several studies have reported the efficacy of lithium in reducing the risk of suicide in patients with $\mathrm{BD}$. A retrospective cohort analysis examined a sample of 20,638 health plan members who were aged $\geq 14$ years, had one or more outpatient diagnosis of BD and had filled a prescription for carbamazepine, divalproex or lithium between January 1994 and December 2001 [57]. Adjusted analyses showed that patients receiving divalproex sodium had a significant 2.7-fold increased risk of successful suicide 
(95\% CI 1.1-6.3; $p=0.03$ ) and 1.7-fold higher risk of nonfatal suicide attempts resulting in hospitalization $(95 \%$ CI $1.2-2.3 ; p=0.002$ ) compared with patients who received lithium [57]. The meta-analysis of randomized controlled trials within the Cochrane Collaboration Depression, Anxiety and Neurosis Controlled Trial Register examined the effect of lithium on the risk of suicide and self-harm and utilized data from 32 trials and more than 3000 patients [58]. Results showed that patients treated with lithium were significantly less likely to die by suicide [odds ratio (OR) $0.26,95 \%$ CI $0.09-0.77 ; p=0.01$ ] or meet the composite endpoint of suicide or self-harm (OR $0.21,95 \%$ CI $0.08-0.50 ; p=0.42$ ) than those not treated with lithium [58]. Similarly, another study reported that risk of suicide/attempted suicide was five times lower [risk ratio (RR) 4.91, $95 \%$ CI 3.82-6.31; $p<0.0001]$ in patients treated with lithium compared with those not treated with lithium [59]. A systematic review and metaanalysis of randomized controlled trials comparing lithium with other drugs in the prevention of mood disorders reported that lithium was effective in reducing the number of suicides (OR 0.13, $95 \%$ CI 0.03-0.66) and deaths from any cause (OR $0.38,95 \%$ CI $0.15-0.95$ ) compared with placebo in patients with bipolar depression [60].

\section{Tolerability Profile of Lithium and Implications of Prolonged-Release Formulations}

Lithium has been reported to be associated with a number of adverse events, including renal damage, thyroid disorders, effects on parathyroid and calcium metabolism, increased bodyweight, gastrointestinal disturbances, central nervous system effects, effects on electrocardiogram and laboratory parameters and an increased risk of reduced urinary concentrating ability [20, 61]. Lithium-associated toxicity and adverse events are related to serum concentrations of lithium and normally occur at concentrations $>1.5-2.0 \mathrm{mmol} / \mathrm{L}[62,63]$. Therefore, therapeutic drug monitoring is an important part of lithium therapy (see Sect. 5). Mild gastrointestinal effects (e.g., nausea) may occur soon after initiating therapy, but usually disappear after the first few days, although fine hand tremors, polyuria and mild thirst may persist [61]. In an overdose situation, which may involve mild symptoms (e.g., nausea, diarrhoea, blurred vision, light-headedness), moderate symptoms (e.g., increasing confusion) or severe symptoms (e.g., coma, convulsions), more severe symptoms may occur after a delay if a PR formulation of lithium has been taken [64].

Some lithium-related adverse events appear to be a function of the rate of increase of serum lithium concentration, which has implications regarding the type of lithium formulation prescribed for a patient [21]. As noted in Sect. 2, the peak:trough ratio is lower with PR than IR formulations of lithium. The slower increase in serum lithium concentrations and lower $C_{\max }$ values with PR versus IR formulations of lithium appear to translate into a reduced rate or degree of severity for some lithium-related adverse events, including tremor, upper gastrointestinal cramping, nausea, rash, cognitive dulling, urinary frequency and neuromuscular slowing [65]. Occasionally there is a worsening of lower gastrointestinal disturbances (e.g., diarrhoea) with PR versus IR formulations of lithium [65].

Lithium PR was associated with a lower incidence of adverse events than lithium IR (9.1 vs $18.3 \%)$ in an observational study in which 47 patients receiving multiple daily administrations of lithium IR (mean dose $719 \mathrm{mg} /$ day) were switched to once-daily administration of lithium PR [mean dose $663 \mathrm{mg} /$ day at 1 month $(n=44)$ ] [66]. After 1 month, all patients reported a preference for lithium PR over lithium IR for its better tolerability and ease of administration [66]. Data from a small $(n=56)$ comparative trial showed that long-term treatment with lithium PR produced less impairment of the ability of the kidney to concentrate urine than lithium IR [67]. In addition, a recent review of the optimal lithium regimen associated with a reduced risk of adverse renal effects in patients with BD indicated that single daily administration of lithium provided benefits compared with multiple daily regimens in some trials, including a reduction in urinary frequency in patients newly started on the drug and less pathological damage to the kidneys observed at renal biopsy [68]. The overall reduction in adverse events with PR versus IR formulations of lithium may lead to a reduced rate of drug discontinuation with $\mathrm{PR}$ formulations, although this has not been evaluated in a controlled clinical trial.

An important clinical issue of renewed interest and recent discussion is that of lithium use during pregnancy [69-72]. Prescribing information states that lithium should not be used during pregnancy, as it may cause foetal harm [73]. An analysis of data from a large primary care database in the UK indicates that very few women were prescribed lithium during pregnancy and only about one-third of women who were being continuously prescribed lithium 3 months prior to pregnancy continued receiving prescriptions for lithium beyond the sixth week of pregnancy [69]. Findings of a prospective cohort study of lithium use during pregnancy showed significantly more miscarriages, preterm deliveries and elective terminations of pregnancy in lithium-exposed pregnancies compared with non-teratogenic-exposed pregnancies [71]. However, there were no significant between-group differences in the rate of major congenital anomalies or in the rate of cardiovascular 
anomalies after excluding cardiovascular anomalies that spontaneously resolved [71]. If it is considered essential to maintain lithium treatment during pregnancy, serum lithium levels should be closely monitored, as renal function changes gradually during pregnancy and suddenly at parturition [70].

Finally, lithium has both antidepressant and antimanic properties and is less teratogenic compared with first-trimester exposure to an anticonvulsant [74]. Of all the mood stabilizers, the greatest amount of evidence exists for lithium and its efficacy in the last months of pregnancy and the months after delivery and the authors found that for most patients with $\mathrm{BD}$, including women of childbearing potential, lithium should be the first-choice treatment [70]. A meta-analysis on the toxicity profile of lithium reported that the risk of congential malformations was uncertain and that the associated risks should be closely monitored before withdrawal of therapy in pregnant women [61]. While the risk of recurrence during the 40 weeks of pregnancy are not greater for pregnant women (compared with nonpregnant women), the risk of recurrence postpartum is increased. The postpartum period appears to be associated with particular risk for women with major affective and psychiatric disorders [75], which underscores the importance of resuming dosing with lithium immediately after delivery (at doses that were previously used by the patient before conception) [70].

Several reports of cognitive impairment with long-term lithium therapy in patients with BD have emerged in the past $[76,77]$. However, continued lithium therapy appears to have minor negative impact on cognition in these patients [78] and a reduction in the dose of lithium may improve overall cognitive functioning [79].

\section{Clinical Management of Lithium Therapy}

Therapeutic drug monitoring is important for optimal use and administration of lithium, as it has a narrow therapeutic range [61]. Dosage should be individualized based on serum lithium concentrations and clinical response. In addition, the dosage required to maintain serum lithium concentrations within the therapeutic range may vary from patient to patient. Although there is some variability in the literature regarding target serum lithium levels, as a general rule, serum lithium levels should be maintained within the range of $0.5-1.0 \mathrm{mmol} / \mathrm{L}$ and should not exceed $1.5 \mathrm{mmol} /$ $\mathrm{L}$ when used as prophylaxis in BD [80]. For the treatment of acute manic or hypomanic episodes and recurrent depressive disorders, a higher target range of $0.8-1.2 \mathrm{mmol} / \mathrm{L}$ (up to a maximum of $1.5 \mathrm{mmol} / \mathrm{L}$ ) is generally recommended. Blood samples for measurement of serum lithium concentrations should be taken just before a dose is due (i.e., trough concentrations) and not less than $12 \mathrm{~h}$ after the previous dose. The first measurement should be 3-7 days after lithium therapy has been started and then weekly until dosage has remained constant for 4 weeks, after which therapeutic drug monitoring can be decreased to every 2-3 months. Conventional IR formulations of lithium are generally administered three times daily with meals [21]. However, the use of a single daily administration of lithium PR or even IR (as an evening dose) has been advocated as an alternative to multiple daily administrations, as it may have an advantage in improving adherence to therapy and appears to have no disadvantages in terms of prophylactic efficacy or adverse events [68, 81]. Interestingly, a recent study focusing on adherence (in diabetes) showed that patients were nine times less likely to adhere to their medications if they received more than once-daily administration of their medication [82]. Indeed, a much older retrospective study showed better rates of adherence in patients who received PR than IR formulations of lithium [83].

Patient non-adherence to lithium treatment is an important issue and there are many reasons for non-adherence, including adverse events (e.g., lethargy and dulling of the senses), missing the highs of mania and being bothered by the idea of having a chronic illness [63, 84-87]. The aforementioned study focusing on adherence (in diabetes) also showed that patients were three times less likely to adhere to their medications if they had concerns about adverse effects [82]. In patients with mood disorders, treatment-related adverse events were also a predictor of non-adherence [88]. Recently reported data from the Lithium Moderate Dose Use Study (LiTMUS) indicated that poor medication adherence in patients with BD was associated with more manic symptoms and adverse events [89].

The use of lithium PR formulations administered once daily has been suggested as one strategy (along with dosage reduction and combination therapy) to reduce nonadherence related to lithium adverse events [65, 90]. Direct comparisons of lithium PR once daily versus multiple daily administration of lithium IR have shown reduced fluctuations in serum lithium concentrations [66, 91, 92] and a reduction in adverse events with the PR formulation [66]; patients also reported a preference for lithium PR versus IR [66]. The severity and prevalence of some lithium-related adverse events appear to be a function of the rate of increase in serum lithium concentrations. As noted in Sect. 4, the slower rate of increase in serum concentrations with PR formulations may reduce adverse events such as tremor, upper gastrointestinal cramping, nausea, rash, cognitive dulling, urinary frequency and neuromuscular slowing, although there may also be an increase in lower gastrointestinal disturbances, such as diarrhoea [21, 65]. 


\section{Conclusion}

Despite the growing use of other agents, lithium remains a central therapy for BD. PR formulations of lithium provide a number of potential advantages over IR formulations, including more stable serum lithium concentrations during the dosage interval and over the long term, a more gradual increase in serum lithium concentrations potentially reducing the risk of certain adverse events and improving adherence, and a more convenient dosage regimen that may also improve adherence to therapy. Thus, PR formulations of lithium may be used over the IR formulations to reduce the treatment-associated adverse events and improve the overall efficacy of lithium in the management of BD. Due to the wide and continued use of lithium therapy in the treatment of $\mathrm{BD}$, future trials comparing compliance rates and adverse events associated with the PR and IR lithium formulations are warranted.

Acknowledgments We would like to thank Greg Plosker, of Springer Healthcare Communications, for providing medical writing assistance. This assistance was funded by Angelini.

\section{Compliance with Ethical Standards}

Declaration of Funding This study was funded by Angelini S.P.A., Italy.

Conflicts of Interest Paolo Girardi declares no conflict of interest. Roberto Brugnoli declares no conflict of interest. Giovanni Manfredi declares no conflict of interest. Gabriele Sani declares no conflict of interest.

Open Access This article is distributed under the terms of the Creative Commons Attribution-NonCommercial 4.0 International License (http://creativecommons.org/licenses/by-nc/4.0/), which permits any noncommercial use, distribution, and reproduction in any medium, provided you give appropriate credit to the original author(s) and the source, provide a link to the Creative Commons license, and indicate if changes were made.

\section{References}

1. Kupfer DJ. The increasing medical burden in bipolar disorder. JAMA. 2005;293(20):2528-30.

2. Kessler RC, Berglund P, Demler O, Jin R, Merikangas KR, Walters EE. Lifetime prevalence and age-of-onset distributions of DSM-IV disorders in the National Comorbidity Survey Replication. Arch Gen Psychiatry. 2005;62(6):593-602.

3. American Psychiatric Association. Diagnostic and statistical manual of mental disorders. 5th ed. Washington, DC, 2013.

4. The National Institute of Mental Health. Bipolar Disorder. http:// www.nimh.nih.gov/health/topics/bipolar-disorder/index.shtml. Accessed 5 June 2015.

5. Zarate CA Jr, Tohen M, Land M, Cavanagh S. Functional impairment and cognition in bipolar disorder. Psychiatr Q. 2000;71(4):309-29.

6. Dickerson FB, Boronow JJ, Stallings CR, Origoni AE, Cole S, Yolken RH. Association between cognitive functioning and employment status of persons with bipolar disorder. Psychiatr Serv. 2004;55(1):54-8. doi:10.1176/appi.ps.55.1.54.

7. MacQueen GM, Young LT, Joffe RT. A review of psychosocial outcome in patients with bipolar disorder. Acta Psychiatr Scand. 2001;103(3):163-70.

8. Osby U, Brandt L, Correia N, Ekbom A, Sparen P. Excess mortality in bipolar and unipolar disorder in Sweden. Arch Gen Psychiatry. 2001;58(9):844-50

9. Gore FM, Bloem PJ, Patton GC, Ferguson J, Joseph V, Coffey C, et al. Global burden of disease in young people aged 10-24 years: a systematic analysis. Lancet. 2011;377(9783):2093-102. doi:10. 1016/s0140-6736(11)60512-6.

10. Merikangas KR, Jin R, He JP, Kessler RC, Lee S, Sampson NA, et al. Prevalence and correlates of bipolar spectrum disorder in the world mental health survey initiative. Arch Gen Psychiatry. 2011;68(3):241-51. doi:10.1001/archgenpsychiatry.2011.12.

11. Carlborg A, Ferntoft L, Thuresson M, Bodegard J. Population study of disease burden, management, and treatment of bipolar disorder in Sweden: a retrospective observational registry study. Bipolar Disord. 2015;17(1):76-85. doi:10.1111/bdi.12234.

12. Malhi GS, Adams D, Cahill CM, Dodd S, Berk M. The management of individuals with bipolar disorder: a review of the evidence and its integration into clinical practice. Drugs. 2009;69(15):2063-101. doi:10.2165/11318850-00000000000000 .

13. Centorrino F, Fogarty KV, Sani G, Salvatore P, Cimbolli P, Baldessarini RJ. Antipsychotic drug use: McLean Hospital, 2002. Hum Psychopharmacol. 2005;20(5):355-8. doi:10.1002/ hup.700.

14. Yatham LN, Kennedy SH, Parikh SV, Schaffer A, Beaulieu S, Alda M, et al. Canadian Network for Mood and Anxiety Treatments (CANMAT) and International Society for Bipolar Disorders (ISBD) collaborative update of CANMAT guidelines for the management of patients with bipolar disorder: update 2013 . Bipolar Disord. 2013;15(1):1-44. doi:10.1111/bdi.12025.

15. Saddichha S, Chaturvedi SK. Clinical practice guidelines in psychiatry: more confusion than clarity? A critical review and recommendation of a unified guideline. ISRN Psychiatry. 2014;. doi:10.1155/2014/828917.

16. Grandjean EM, Aubry JM. Lithium: updated human knowledge using an evidence-based approach: Part I: clinical efficacy in bipolar disorder. CNS Drugs. 2009;23(3):225-40. doi:10.2165/ 00023210-200923030-00004.

17. Malhi GS, Tanious M, Das P, Berk M. The science and practice of lithium therapy. Aust NZ J Psychiatry. 2012;46(3):192-211. doi:10.1177/0004867412437346.

18. Grof P. Sixty years of lithium responders. Neuropsychobiology. 2010;62(1):8-16. doi:10.1159/000314305.

19. Malhi GS, Tanious M, Das P, Coulston CM, Berk M. Potential mechanisms of action of lithium in bipolar disorder. Current understanding. CNS Drugs. 2013;27(2):135-53. doi:10.1007/ s40263-013-0039-0.

20. Grandjean EM, Aubry JM. Lithium: updated human knowledge using an evidence-based approach: Part III: clinical safety. CNS Drugs. 2009;23(5):397-418. doi:10.2165/00023210-20092305000004.

21. Grandjean EM, Aubry JM. Lithium: updated human knowledge using an evidence-based approach. Part II: clinical pharmacology and therapeutic monitoring. CNS Drugs. 2009;23(4):331-49.

22. Sanofi. Priadel (lithium carbonate) prolonged release tablets: summary of product characteristics. 2015. http://www.medicines. org.uk. Accessed 5 June 2015.

23. Fyro B, Pettersson U, Sedvall G. Serum lithium levels and side effects during administration of lithium carbonate and two slow release lithium preparations to human volunteers. Pharmacologia Clinica. 1970;2:236-40. 
24. Gitlin M. Lithium and the kidney: an updated review. Drug Saf. 1999;20(3):231-43.

25. Morrison JM Jr, Pritchard HD, Braude MC, D'Aguanno W. Plasma and brain lithium levels after lithium carbonate and lithium chloride administration by different routes in rats. Proc Soc Exp Biol Med. 1971;137(3):889-92.

26. Hillert M, Zimmermann M, Klein J. Uptake of lithium into rat brain after acute and chronic administration. Neurosci Lett. 2012;521(1):62-6. doi:10.1016/j.neulet.2012.05.060.

27. Ward ME, Musa MN, Bailey L. Clinical pharmacokinetics of lithium. J Clin Pharmacol. 1994;34(4):280-5.

28. GlaxoSmithKline. Liskonum tablets (controlled-release lithium carbonate): summary of product characteristics. 2015. https:// www.medicines.org.uk. Accessed 5 June 2015.

29. Poolsup N, Li Wan Po A, de Oliveira IR. Systematic overview of lithium treatment in acute mania. J Clin Pharm Ther. 2000;25(2):139-56.

30. Bowden CL, Brugger AM, Swann AC, Calabrese JR, Janicak PG, Petty F, et al. Efficacy of divalproex vs lithium and placebo in the treatment of mania. The Depakote Mania Study Group. Jama. 1994;271(12):918-24.

31. Bowden CL, Grunze H, Mullen J, Brecher M, Paulsson B, Jones $\mathrm{M}$, et al. A randomized, double-blind, placebo-controlled efficacy and safety study of quetiapine or lithium as monotherapy for mania in bipolar disorder. J Clin Psychiatry. 2005;66(1):111-21.

32. Kushner SF, Khan A, Lane R, Olson WH. Topiramate monotherapy in the management of acute mania: results of four double-blind placebo-controlled trials. Bipolar Disord. 2006;8(1):15-27. doi:10.1111/j.1399-5618.2006.00276.x.

33. Storosum JG, Wohlfarth T, Schene A, Elferink A, van Zwieten BJ, van den Brink W. Magnitude of effect of lithium in shortterm efficacy studies of moderate to severe manic episode. Bipolar Disord. 2007;9(8):793-8. doi:10.1111/j.1399-5618.2007. 00445.x.

34. Segal J, Berk M, Brook S. Risperidone compared with both lithium and haloperidol in mania: a double-blind randomized controlled trial. Clin Neuropharmacol. 1998;21(3):176-80.

35. Berk M, Ichim L, Brook S. Olanzapine compared to lithium in mania: a double-blind randomized controlled trial. Int Clin Psychopharmacol. 1999;14(6):339-43.

36. Tohen M, Chengappa KN, Suppes T, Zarate CA Jr, Calabrese JR, Bowden CL, et al. Efficacy of olanzapine in combination with valproate or lithium in the treatment of mania in patients partially nonresponsive to valproate or lithium monotherapy. Arch Gen Psychiatry. 2002;59(1):62-9.

37. Yatham LN, Grossman F, Augustyns I, Vieta E, Ravindran A. Mood stabilisers plus risperidone or placebo in the treatment of acute mania. International, double-blind, randomised controlled trial. Br J Psychiatry. 2003;182:141-7.

38. Yatham LN, Paulsson B, Mullen J, Vagero AM. Quetiapine versus placebo in combination with lithium or divalproex for the treatment of bipolar mania. J Clin Psychopharmacol. 2004;24(6):599-606.

39. Bourin MS, Severus E, Schronen JP, Gass P, Szamosi J, Eriksson $\mathrm{H}$, et al. Lithium as add-on to quetiapine $\mathrm{XR}$ in adult patients with acute mania: a 6-week, multicenter, double-blind, randomized, placebo-controlled study. Int J Bipolar Disord. 2014;2:14. doi:10. 1186/s40345-014-0014-9.

40. Bowden CL, Calabrese JR, McElroy SL, Gyulai L, Wassef A, Petty F, et al. A randomized, placebo-controlled 12-month trial of divalproex and lithium in treatment of outpatients with bipolar I disorder. Divalproex Maintenance Study Group. Arch Gen Psychiatry. 2000;57(5):481-9.

41. Calabrese JR, Bowden CL, Sachs G, Yatham LN, Behnke K, Mehtonen OP, et al. A placebo-controlled 18-month trial of lamotrigine and lithium maintenance treatment in recently depressed patients with bipolar I disorder. J Clin Psychiatry. 2003;64(9):1013-24.

42. Bowden CL, Calabrese JR, Sachs G, Yatham LN, Asghar SA, Hompland M, et al. A placebo-controlled 18-month trial of lamotrigine and lithium maintenance treatment in recently manic or hypomanic patients with bipolar I disorder. Arch Gen Psychiatry. 2003;60(4):392-400. doi:10.1001/archpsyc.60.4.392.

43. Geddes JR, Goodwin GM, Rendell J, Azorin JM, Cipriani A, Ostacher MJ, et al. Lithium plus valproate combination therapy versus monotherapy for relapse prevention in bipolar I disorder (BALANCE): a randomised open-label trial. Lancet. 2010;375(9712):385-95. doi:10.1016/s0140-6736(09)61828-6.

44. Weisler RH, Nolen WA, Neijber A, Hellqvist A, Paulsson B. Continuation of quetiapine versus switching to placebo or lithium for maintenance treatment of bipolar I disorder (Trial 144: a randomized controlled study). J Clin Psychiatry. 2011;72(11):1452-64. doi:10.4088/JCP.11m06878.

45. Tondo L, Baldessarini RJ, Hennen J, Floris G. Lithium maintenance treatment of depression and mania in bipolar I and bipolar II disorders. Am J Psychiatry. 1998;155(5):638-45. doi:10.1176/ ajp.155.5.638.

46. Berghofer A, Alda M, Adli M, Baethge C, Bauer M, Bschor T, et al. Long-term effectiveness of lithium in bipolar disorder: a multicenter investigation of patients with typical and atypical features. J Clin Psychiatry. 2008;69(12):1860-8.

47. Geddes JR, Burgess S, Hawton K, Jamison K, Goodwin GM. Long-term lithium therapy for bipolar disorder: systematic review and meta-analysis of randomized controlled trials. Am J Psychiatry. 2004;161(2):217-22.

48. ISRCTN registry. OxLith: exploration of the short-term physical and psychological effects of lithium in mood instability. 2015. http:// www.isrctn.com/ISRCTN91624955. Accessed 08 July 2016.

49. Coryell W. Rapid cycling bipolar disorder: clinical characteristics and treatment options. CNS Drugs. 2005;19(7):557-69.

50. Goodwin FK. Rationale for using lithium in combination with other mood stabilizers in the management of bipolar disorder. J Clin Psychiatry. 2003;64(Suppl 5):18-24.

51. Goodwin FK, Murphy DL, Bunney WE Jr. Lithium-carbonate treatment in depression and mania. A longitudinal double-blind study. Arch Gen Psychiatry. 1969;21(4):486-96.

52. Mendels J. Lithium in the treatment of depression. Am J Psychiatry. 1976;133(4):373-8. doi:10.1176/ajp.133.4.373.

53. Baron M, Gershon ES, Rudy V, Jonas WZ, Buchsbaum M. Lithium carbonate response in depression. Prediction by unipolar/ bipolar illness, average-evoked response, catechol-O-methyl transferase, and family history. Arch Gen Psychiatry. 1975;32(9):1107-11.

54. Young AH, McElroy SL, Bauer M, Philips N, Chang W, Olausson B, et al. A double-blind, placebo-controlled study of quetiapine and lithium monotherapy in adults in the acute phase of bipolar depression (EMBOLDEN I). J Clin Psychiatry. 2010;71(2):150-62. doi:10.4088/JCP.08m04995gre.

55. McElroy SL, Weisler RH, Chang W, Olausson B, Paulsson B, Brecher $\mathrm{M}$, et al. A double-blind, placebo-controlled study of quetiapine and paroxetine as monotherapy in adults with bipolar depression (EMBOLDEN II). J Clin Psychiatry. 2010;71(2):163-74. doi:10.4088/JCP.08m04942gre.

56. Haeberle A, Greil W, Russmann S, Grohmann R. Mono- and combination drug therapies in hospitalized patients with bipolar depression. Data from the European drug surveillance program AMSP. BMC Psychiatry. 2012;12:153. doi:10.1186/1471-244x12-153.

57. Goodwin FK, Fireman B, Simon GE, Hunkeler EM, Lee J, Revicki D. Suicide risk in bipolar disorder during treatment with lithium and divalproex. JAMA. 2003;290(11):1467-73. doi:10. 1001/jama.290.11.1467. 
58. Cipriani A, Pretty H, Hawton K, Geddes JR. Lithium in the prevention of suicidal behavior and all-cause mortality in patients with mood disorders: a systematic review of randomized trials. Am J Psychiatry. 2005;162(10):1805-19. doi:10.1176/appi.ajp. 162.10.1805.

59. Baldessarini RJ, Tondo L, Davis P, Pompili M, Goodwin FK, Hennen J. Decreased risk of suicides and attempts during longterm lithium treatment: a meta-analytic review. Bipolar Disord. 2006;8(5 Pt 2):625-39. doi:10.1111/j.1399-5618.2006.00344.x.

60. Cipriani A, Hawton K, Stockton S, Geddes JR. Lithium in the prevention of suicide in mood disorders: updated systematic review and meta-analysis. BMJ. 2013;346:f3646.

61. McKnight RF, Adida M, Budge K, Stockton S, Goodwin GM, Geddes JR. Lithium toxicity profile: a systematic review and meta-analysis. Lancet. 2012;379(9817):721-8. doi:10.1016/ S0140-6736(11)61516-X.

62. Speirs J, Hirsch SR. Severe lithium toxicity with "normal" serum concentrations. Br Med J. 1978;1(6116):815-6.

63. Mitchell PB. Therapeutic drug monitoring of psychotropic medications. Br J Clin Pharmacol. 2000;49(4):303-12.

64. Friedberg RC, Spyker DA, Herold DA. Massive overdoses with sustained-release lithium carbonate preparations: pharmacokinetic model based on two case studies. Clin Chem. 1991;37(7):1205-9.

65. Bowden CL. Key treatment studies of lithium in manic-depressive illness: efficacy and side effects. J Clin Psychiatry. 1998;59 Suppl 6:13-9; discussion 20.

66. Durbano F, Mencacci C, Dorigo D, Riva M, Buffa G. The longterm efficacy and tolerability of carbolithium once a day: an interim analysis at 6 months. Clin Ter. 2002;153(3):161-6.

67. Wallin L, Alling C. Effect of sustained-release lithium tablets on renal function. Br Med J. 1979;2(6201):1332.

68. Carter L, Zolezzi M, Lewczyk A. An updated review of the optimal lithium dosage regimen for renal protection. Can J Psychiatry. 2013;58(10):595-600.

69. McCrea RL, Nazareth I, Evans SJ, Osborn DP, Pinfold V, Cowen PJ, et al. Lithium prescribing during pregnancy: a UK primary care database study. PLoS One. 2015;10(3):e0121024. doi:10. 1371/journal.pone.0121024.

70. Bergink V, Kushner SA. Lithium during pregnancy. Am J Psychiatry. 2014;171(7):712-5. doi:10.1176/appi.ajp.2014. 14030409.

71. Diav-Citrin O, Shechtman S, Tahover E, Finkel-Pekarsky V, Arnon J, Kennedy D, et al. Pregnancy outcome following in utero exposure to lithium: a prospective, comparative, observational study. Am J Psychiatry. 2014;171(7):785-94. doi:10.1176/appi. ajp.2014.12111402.

72. Barbui C, Bertolazzi A, Hanife B, Cipriani A. Treatment choices in women with bipolar disorder seeking pregnancy: a clinical case illustration. Case Rep Psychiatry. 2013;2013:630732. doi: $10.1155 / 2013 / 630732$.

73. GlaxoSmithKline. Prescribing information. 2003. http://www. accessdata.fda.gov/drugsatfda_docs/label/2004/16860slr074,181 52slr020_eskalith_lbl.pdf. Accessed 11 July 2016.

74. Altshuler L, Richards M, Yonkers K. Treating bipolar disorder during pregnancy: evidence-based review. Curr Psychiatry. 2003;2(7):14-26.

75. Viguera AC, Nonacs R, Cohen LS, Tondo L, Murray A, Baldessarini RJ. Risk of recurrence of bipolar disorder in pregnant and nonpregnant women after discontinuing lithium maintenance. Am J Psychiatry. 2000;157(2):179-84. doi:10.1176/appi.ajp.157. 2.179 .
76. Pachet AK, Wisniewski AM. The effects of lithium on cognition: an updated review. Psychopharmacology. 2003;170(3):225-34. doi:10.1007/s00213-003-1592-x.

77. Squire LR, Judd LL, Janowsky DS, Huey LY. Effects of lithium carbonate on memory and other cognitive functions. Am J Psychiatry. 1980;137(9):1042-6. doi:10.1176/ajp.137.9.1042.

78. Wingo AP, Wingo TS, Harvey PD, Baldessarini RJ. Effects of lithium on cognitive performance: a meta-analysis. J Clin Psychiatry. 2009;70(11):1588-97. doi:10.4088/JCP.08r04972.

79. Kocsis JH, Shaw ED, Stokes PE, Wilner P, Elliot AS, Sikes C, et al. Neuropsychologic effects of lithium discontinuation. J Clin Psychopharmacol. 1993;13(4):268-75.

80. Severus WE, Kleindienst N, Seemuller F, Frangou S, Moller HJ, Greil W. What is the optimal serum lithium level in the long-term treatment of bipolar disorder-a review? Bipolar Disord. 2008;10(2):231-7. doi:10.1111/j.1399-5618.2007.00475.x.

81. Ljubicic D, Letica-Crepulja M, Vitezic D, Bistrovic IL, Ljubicic R. Lithium treatments: single and multiple daily dosing. Can J Psychiatry. 2008;53(5):323-31.

82. Jarab AS, Almrayat R, Alqudah S, Thehairat E, Mukattash TL, Khdour M, et al. Predictors of non-adherence to pharmacotherapy in patients with type 2 diabetes. Int $\mathbf{J}$ Clin Pharm. 2014;36(4):725-33. doi:10.1007/s11096-014-9938-5.

83. Lavantes B, Senimon F, Bayle FJ. Compliance with and tolerance of sustained-release lithium carbonate. Encephale. 1999;25(2):152-7.

84. Goodwin GM. Prophylaxis of bipolar disorder: how and who should we treat in the long term? Eur Neuropsychopharmacol. 1999;9(Suppl 4):S125-9.

85. Crowe M, Wilson L, Inder M. Patients' reports of the factors influencing medication adherence in bipolar disorder-an integrative review of the literature. Int $\mathrm{J}$ Nurs Stud. 2011;48(7):894-903. doi:10.1016/j.ijnurstu.2011.03.008.

86. Velligan DI, Weiden PJ, Sajatovic M, Scott J, Carpenter D, Ross $\mathrm{R}$, et al. Strategies for addressing adherence problems in patients with serious and persistent mental illness: recommendations from the expert consensus guidelines. J Psychiatr Pract. 2010;16(5):306-24. doi:10.1097/01.pra.0000388626.98662.a0.

87. de Souza C, Vedana KG, Mercedes BP, Miasso AI. Bipolar disorder and medication: adherence, patients' knowledge and serum monitoring of lithium carbonate. Rev Latino-Am Enferm. 2013;21(2):624-31.

88. Pompili M, Venturini P, Palermo M, Stefani H, Seretti ME, Lamis DA, et al. Mood disorders medications: predictors of nonadherence-review of the current literature. Expert Rev Neurother. 2013;13(7):809-25. doi:10.1586/14737175.2013. 811976.

89. Sylvia LG, Reilly-Harrington NA, Leon AC, Kansky CI, Calabrese JR, Bowden CL, et al. Medication adherence in a comparative effectiveness trial for bipolar disorder. Acta Psychiatr Scand. 2014;129(5):359-65. doi:10.1111/acps.12202.

90. Dunner DL. Lithium carbonate: maintenance studies and consequences of withdrawal. J Clin Psychiatry. 1998;59 Suppl 6:48-55; discussion 6.

91. Castrogiovanni P. A novel slow-release formulation of lithium carbonate (carbolithium once-a-day) vs. standard carbolithium: a comparative pharmacokinetic study. Clin Ter. 2002;153(2):107-15.

92. Keck PE Jr, McElroy SL, Bennett JA. Pharmacologic loading in the treatment of acute mania. Bipolar Disord. 2000;2(1):42-6. 